\title{
O Mapa de Ausências e Apagamentos em A Rua dos Crocodilos, de Bruno
}

\author{
Schulz \\ Camila Backes dos Santos* \\ Universidade Feevale, Novo Hamburgo, RS, Brasil \\ ORCID: https://orcid.org/0000-0001-7276-8252 \\ Simone Zanon Moschen** \\ Universidade Federal do Rio Grande do Sul - UFRGS, Porto alegre, RS, Brasil \\ ORCID: https://orcid.org/0000-0003-3776-8737
}

\section{RESUMO}

Este trabalho procura colocar em destaque, por meio da narrativa do escritor polonês Bruno Schulz, um operador possível para o enlace entre psicanálise e literatura: o texto (o romance literário ou uma vida narrada em análise) como resultante da impossibilidade de representar o real. A leitura de Schulz, guiada pela bússola da teoria psicanalítica de Freud e Lacan, permite com que se acentue o que chamamos de "mapa de ausências e apagamentos", elemento presente e transversalizador na compilação dos quinze contos que integram A rua dos Crocodilos. Esse mapa traça as linhas de um território no qual é possível realçar as reverberações do conceito de estranho de Freud e, com ele, refletir sobre os efeitos de leitura produzidos pela obra do escritor polonês.

Palavras-chave: literatura, psicanálise, apagamento, ausência, real.

\section{The Map of Absences and Obliterations in Bruno Schulz's The Street Of}

\section{Crocodiles}

\begin{abstract}
This paper aims to highlight, trough the narrative of the polish writer Bruno Schulz, a possible operator for the link between psychoanalysis and literature: text (literary novel or a life narrated in analysis) as the result of the impossibility to represent real. The reading of Schulz with the guidelines from Freud's and Lacan's psychoanalytic theories let us examine what we have called "map of absences and obliterations" in the compilation of fifteen short stories The street of croocodiles. This map traces the lines of a territory in which is possible to highlight the reverberations of Freud's concept of strange, and enable us to reflect upon the effects of the reading Schulz's works.
\end{abstract}

Keywords: literature, psychoanalysis, obliteration, absence, real.

ISSN 1808-4281 


\section{El Mapa de Ausencias y Eliminaciones en La Rua de Los Crocodilos, de}

\section{Bruno Schulz}

\section{RESUMEN}

El presente trabajo forma parte de una investigación más amplia, inspirada en la vida y obra de Bruno Schulz, que se propone pensar el proyecto artístico y literario del escritor norteamericano Jonathan Safran Foer, llamado Tree of codes (2010). En este artículo, partiendo de la obra de Schulz La calle de los cocodrilos, nos dedicamos a reflexionar sobre la relación entre el psicoanálisis y lo que denominamos "mapa de ausencias y eliminaciones", presente en esa compilación de 15 cuentos del escritor polaco. Esa relación nos permitirá establecer un operador posible para el enlace entre psicoanálisis y literatura: el texto (la novela literaria o una vida narrada en análisis) como resultante de la imposibilidad de representar lo real.

Palabras clave: literatura, psicoanálisis, eliminación, ausencia, real.

O ensaio de Coetzee (2011) sobre Bruno Schulz (1892-1942) começa nos remetendo a uma imagem da infância do escritor:

Numa das suas memórias mais remotas da infância, o jovem Bruno Schulz está sentado no chão, cercado pela admiração de vários membros de sua família, enquanto rabisca um "desenho" atrás do outro em velhas folhas de jornal. Entregue a seu arrebatamento criador, a criança ainda vive uma "era da genialidade", ainda tem um acesso desprovido de censura ao domínio do mito. Ou pelo menos é isso que pensaria o homem em que essa criança se tornou; todo o seu esforço da maturidade seria no sentido de recuperar o contato com esses seus poderes iniciais, e amadurecer infância adentro. (Coetzee, 2011, p. 66).

Coetzee nos lembra de uma característica muito singular da escrita de Schulz: sua relação com uma percepção tenra da infância, quando, ainda no arrebatamento criador de uma criança desprovida de censura, inicia seus caminhos pelo domínio do mito. Talvez tenha sido o que seguiu perseguindo ao longo de toda a sua vida, num amadurecer infância adentro. Momento em que a criança apenas se entrega quieta a observar seu entorno, aquele espaço da convivência familiar, que para ela é todo o universo. Os contos de Schulz falam sobre a simplicidade de um cotidiano, porém de forma extremamente rebuscada e fragmentada, talvez como o quebra-cabeças colorido através do qual uma criança enxerga o mundo. 
Schulz foi o terceiro filho de uma família de judeus da classe mercantil. Nascido no ano de 1892, na Galícia, região da Polônia, faz parte de um rol de escritores - entre eles Italo Svevo, Robert Walser, Joseph Roth, Sándor Márai, Robert Musil e Walter Benjamin - que nasceram na Europa no final do século XIX e vivenciaram, na juventude, ou já no final da vida, o horror da Primeira Guerra Mundial, tendo alguns deles ainda atravessado a Segunda Guerra Mundial. Mesmo com diferentes origens nacionais e étnicas, o que os aproxima é o fato de que todos sentiram a necessidade de explorar, na ficção, a extinção do mundo em que tinham nascido; todos registraram as ondas de choque do novo mundo que emergia. Suas origens burguesas não os isentaram das tributações do exílio, da destituição e, às vezes, da violência pessoal (Attridge, 2011). No caso de Schulz, o preço pago foi ainda mais alto, pois teve sua vida e sua obra exterminadas pelo nazismo. A única coisa pior do que a morte é o esquecimento.

Quando os alemães cercaram Drohobycz, em 1941, Schulz, com medo de perder sua obra, empacotou e distribuiu os originais para que amigos não judeus os guardassem. De tudo, perdeu-se a maior parte. Felix Landau, um oficial da Gestapo responsável por Schulz, descobriu que ele era desenhista e pediu que desenhasse as paredes do quarto de brinquedos de seus filhos. Pelos desenhos Schulz era pago com alimentos. A relação com esse oficial oferecia a Schulz privilégios e uma proteção importante, por ser um “judeu necessário”. Em novembro de 1942, Landau matou um "protegido" de outro oficial alemão, Karl Gunther, e teve como vingança a morte de Schulz por este oficial. Na esquina entre as ruas Czacki e Mickiewicz, Karl Gunther atirou na cabeça de Bruno Schulz: "Você matou o meu judeu, agora matei o seu.", disse para Landau. Por um tempo, Schulz conseguiu manter-se a salvo pela proteção de Landau. A faixa de "judeu necessário" no braço de Schulz o protegeu até 1942, quando foi fuzilado. Em 1943, não restava mais nenhum judeu em Drohobycz. Milosz (1989/2012, p. 9) comenta: "Jamais estive na pequena cidade de Drohobycz e tampouco conheci pessoalmente Bruno Schulz. Mesmo assim, nos círculos de jovens poetas poloneses que eu frequentava no final da década de 1930, o nome dele ressoava com uma aura distinta e mágica". Jerzy Ficowsky, biógrafo de Schulz, define-o como o último expoente notável da arte epistolar na Polônia. "Quando hoje penso nisso”, aponta Milosz (1989/2012, p. 9), "reconheço nesse fenômeno de respeito inicial e instintivo a confirmação de uma regra: em geral, é certo sentimento pela estatura excepcional de um artista o que anuncia seu renome futuro".

Para a tradutora da obra de Schulz do polonês para o inglês, Celina Wieniewska (como citado em Coetzee 2011, p. 69), o mundo de Schulz era basicamente o seu mundo privado, no 
qual, ao centro, estava seu pai, o "incorrigível improvisador": o herói que sozinho fez frente à guerra que assolou a cidade de Drohobycz, figura por vezes assemelhada à personagem de um profeta bíblico nas histórias do autor, mas que era, na verdade, um simples comerciante que herdou um mercado, o qual administrou até o momento de seu adoecimento, quando teve de abandoná-lo aos cuidados da mulher. Schulz formava junto com seus amigos a tríade dos mais ousados experimentalistas poloneses: Stanislaw Ignacy Witkiewicz, que se suicidou em dezembro de 1939, e Witold Grombrowicz, que sobreviveu na Argentina após a Shoah. Para Milosz (1989/2012), a dificuldade de trabalhar com o legado de Schulz poderia residir no fato de que sua singularidade se mostra na percepção de um caminho que só poderia ser trilhado por ele, e que, de fato, não foi percorrido por mais ninguém. Uma singularidade que poderia ser lida como o trabalhado de análise de um paciente em um divã, com seus medos, sonhos, angústias e amores.

Schulz fala de uma construção enigmática que captura e nos aproxima no que se refere aos descaminhos da linguagem e à aproximação com o inconsciente. A vida social e em família, a descoberta da criação artística, do amor e da morte - tudo é descrito de forma a criar quadros imagéticos próximos ao sonho. O universo enigmático de Schulz é lido com muito interesse por autores de uma geração posterior à sua, como Philip Roth e J. M. Coetzee. Sua literatura é considerada intraduzível: "a exuberância, a opulência de sua prosa barroca o distingue do ascético Kafka, e o leva à beira da intraduzibilidade" (Milosz, 1989/2012, p. 10). Apesar de judeu, Schulz sempre escreveu em polonês (morreu na Polônia como um judeu). Na opinião de Isaac Bashevis Singer (como citado em Milosz, 1989/2012, p. 9), os escritores poloneses de formação judaica agiam, por assim dizer, "ao arrepio de tal formação", e por esse motivo a linguagem deles era literária demais, quando não de uma rigidez absoluta.

Por ofício, Bruno Schulz era um professor de desenho; como escritor, era um prosador “cuja preocupação com a linguagem ia muito além do normal” (Milosz, 1989/2012, p. 10). Para Schulz, a filosofia "é na realidade uma filologia, uma profunda e criativa investigação da palavra" (Milosz, 1989/2012, p. 10) e a função da poesia (referindo-se com razão à própria obra) era restituir a perdida dimensão original e mítica das palavras, as quais comparou aos fragmentos do corpo de uma serpente lendária. A serpente foi cortada em pedaços e seus fragmentos buscam uns aos outros. Schulz, ainda nas palavras de Milosz, era especialmente sensível ao mau gosto, ao falso brilho e à hipocrisia da população do século XX, então ascendente na Europa provinciana. Seu sentimento de decadência não é menor que o de Kafka ao descrever o sentimento em relação a uma modernidade crescente. Schulz, como num sonho, escreve sobre aquilo que mais lhe provoca fascínio, tudo o que é normalmente 
descartado como inferior, como escória, refugo, coisas de segunda mão, tanto no sentido material quanto no de maneiras de se comportar.

Schulz perseguia uma realidade em estado de fermentação, mudança, fluidez, para ele, o sentido do mundo consistia no que chamava de "um monismo específico da substância na qual objetos particulares não passam de máscaras”. Tais máscaras aparecem por um instante e logo são repudiadas. Essa é a origem do humor e da ironia como ingredientes permanentes da narração, pois cada objeto e cada ação deixam transparecer, no momento em que se materializam, a própria instabilidade, o papel que temporariamente assumem. (Milosz, 1989/2012, p. 11)

Em A tempestade, última peça escrita por Shakespeare (n.d.), encontramos que os homens são feitos daquela mesma matéria de que são feitos os sonhos, e não é à toa que Freud, em toda a sua obra, indica o sonho como a "via régia" para o inconsciente. O encontro com a obra de Schulz nos leva a um lugar do inconsciente, do sonho, do não dito, daquilo que não está explícito, mas se busca. Podemos pensar que o sentimento de não pertencimento a um lugar próprio faz com que o buscar um lugar para amadurecer infância adentro seja uma forma de contornar a exclusão na qual sempre viveu. Ter no horizonte da escrita um lugar da infância talvez seja como reconciliar-se com a memória afetiva, tal qual nos propõe Walter Benjamin (1938/2000, p. 239) ao afirmar que “a busca, mesmo que em vão, é tão importante quanto o achado feliz".

Schulz passou a ser conhecido quando A rua dos crocodilos foi traduzido para o inglês por Celina Wieniewska, em 1963. Hoje, a obra de Schulz já foi traduzida para mais de trinta idiomas. Muito se produziu em cima da vida e da obra de Bruno Schulz - talvez não muito no Brasil, pois sua obra só foi traduzida para o português em 2012. Muitos escritores, entre eles Philip Roth, foram também responsáveis por apresentar ao mundo o "gênio polonês". Isaac Bashevis Singer fez uma breve resenha, "A polish Franz Kafka", publicada no The New York Times em 9 de julho de 1978, acerca da edição americana de Sanatório. J. M. Coetzee, em "Bruno Schulz", publicado em seu livro de ensaios literários Mecanismos internos, descreve a trajetória biográfica e literária de Schulz e relativiza as frequentes comparações entre sua obra e a de Kafka.

Tendo situado a atmosfera em que Schulz produz sua obra, seguiremos na direção de situar aquilo que de sua escrita nos parece interessar ao campo de estudos da ficção e da psicanálise de Freud e Lacan. Afinal, quando recolhemos os efeitos de leitura produzidos pela 
obra de Bruno Schulz não podemos deixar de lembrar que, pelo seu trágico desfecho da vida, resgatar sua escrita é também um trabalho de memória, de resistência frente ao terror produzido pela Shoah.

\section{A rua dos Crocodilos}

A rua dos Crocodilos é uma reunião de quinze histórias curtas que foram publicadas pela primeira vez em polonês sob o título de Sklepy Cynamonowe (Lojas de canela), em 1933, tendo sido traduzida para o inglês apenas em 1977, sob o título The Street of Crocodiles (A rua dos Crocodilos). Os contos foram escritos provavelmente em torno de 1932, por meio de cartas que Bruno Schulz escrevia para uma amiga poeta, que vivia em Lvov. "Suas cartas se metamorfosearam, transformando-se em fragmentos de uma prosa poética deslumbrante" (Ficowski, 2004/1963, p. 15). Os contos, ou a compilação de todas as histórias, narram, aos olhos do personagem principal, menino, o encontro de um pai com a loucura: à medida que os contos avançam e o tempo passa, o pai vai cada vez mais perdendo a razão. O texto de apresentação da edição brasileira da ficção completa de Bruno Schulz (2012) acrescenta:

As histórias se entrelaçam pela figura de um mesmo narrador, o menino e depois adolescente Józef, e têm como cenário uma cidade provinciana que vivencia o avanço do capitalismo e os últimos tempos do império austro-húngaro. Num estilo que se aproxima da poesia, as palavras aqui não estão a serviço da mimese; antes, parecem forjar uma realidade própria. (Schulz, 2012).

O fato de todos os contos terem o mesmo narrador, o menino Józef, e manterem a mesma linha temática - a doença do pai, o cotidiano familiar, as descobertas juvenis e uma aguçada e sensível percepção da realidade em tom altamente descritivo ao olhar de uma criança - faz com que A rua dos Crocodilos possa ser considerado um romance. A preocupação com a forma era evidente em Schulz. Gombrowicz (1961/2012, p. 391) refere-se a Schulz como atento a uma perdição da forma. Os contos são fortemente marcados pelo caráter descritivo, e tanto sentimentos quanto ambientes são construídos como se cada palavra tivesse sido minuciosamente escolhida para ocupar determinado espaço no seu contexto. Escolher Schulz é como fazer uma escolha por um ponto de partida que se justifica pela riqueza vocabular e por todo o arranjo e composição de palavras. A troca do conto que daria 
nome ao romance também não é ao acaso. O título passa de Lojas de canela para A rua dos Crocodilos, e essa é uma mudança importante.

Para Wurth (2011, p. 3), se "Lojas de canela" narra uma viagem em tom de nostalgia e bons aromas pelas ruas de Drohobicz, em A rua dos Crocodilos, a rua é vulgar, mesquinha, poluída, e a comercialização é barata. É como se a cor passasse de colorida a tons de cinza. "O ar exalava uma primavera secreta, uma brancura inexprimível de neve e violetas. Entramos numa área de colinas. A linha dos outeiros hirsutos com as vergas nuas de árvores levantava-se ao céu como um suspiro de deleite." (Schulz, 1934/2008, p. 81). "A rua dos Crocodilos" é um conto mitológico e começa da seguinte maneira, tentando formar uma imagem de um lugar e nos dando alguns contornos de um mapa:

Meu pai guardava, na gaveta mais baixa de sua profunda escrivaninha, um velho e belo mapa da nossa cidade. Era um volume inteiro de folhas de pergaminho dobradas ao meio, que antes ligadas por pedaços de pano formavam um enorme mapa de parede, uma vista aérea panorâmica. Pendurado na parede, ocupava quase todo o espaço do quarto e abria uma vista imensa para todo o vale do rio Tsymienica. (Schulz, 1934/2008, pp. 83)

A descrição transcorre em tom poético, estilo barroco, em uma linguagem corpulenta e abstrata. Conduz seu leitor pelas ruas de um mapa através dos olhos de Jozéf, que tem em torno de 10 anos, acompanhado de seu pai Jacub. O conto "A rua dos Crocodilos" nos aproxima desse lugar, que no mapa da cidade apresenta-se em branco (como as regiões polares): a rua dos Crocodilos é uma região ausente no mapa. Há, nesse conto, um enigma: a região onde fica essa rua não possui representação no mapa, mas, ao mesmo tempo, é descrita como um lugar que comporta tudo que está em excesso. As pessoas, o tráfego, o comércio, tudo que ali figura carrega um traço do excessivo. $\mathrm{O}$ conto assume uma posição crítica diante do modernismo nascente e da nova forma de comércio que surgia na cidade. Nossa leitura de "A rua dos Crocodilos" é guiada por duas sensações: uma delas fala de um movimento que nos empurra, tal qual a força que age em um imã, uma força de imantação que nos leva a uma região de excessos e apagamentos, o que acaba por produzir em nós uma sensação de estranhamento e familiaridade ao nos aproximar de um silêncio excessivo. Outra, toca-nos naquilo que nos remete a uma relação com os desvios: um caminhar errante sempre dará contornos a uma experiência singular, algo que resiste à representação cartográfica. 


\section{O estranho em "A rua dos Crocodilos"}

Ninguém impede a saída da rua dos Crocodilos, a via larga de edifícios modernos e mal-acabados que se estende até a estação ferroviária. O dia, bem como o bairro, está cinzento, também monocromático, como é comum nessa funesta região. "Tremem nessa epiderme a tensão da pose, a seriedade artificial da máscara, e o páthos irônico. Mas não temos a menor vontade de desmascarar tal espetáculo. Apesar do nosso conhecimento sublime, sentimo-nos envolvidos na magia barata do bairro." (Schulz, 1934/2008, p. 88). Observamos também em "A rua dos Crocodilos" uma relação entre o desejo e o estranho, como o proposto freudiano. Um lugar onde tudo pode e todo escárnio é possível e permitido, ao mesmo tempo em que, nefasto e sombrio, exerce tremendo fascínio sobre os transeuntes, como se sentissem um chamado de peregrinar por suas entranhas. Os transeuntes se misturam

com a rua. É como se, ao sermos tomados por esse silêncio da multidão (multidão silenciosa), perdêssemos o chão e acabássemos por nos misturar com a rua. Sofremos uma despersonalização, quando o eu se mistura com o espaço ao sermos atravessados pelo silêncio no mapa.

Tal sensação de estranho e familiar também está em relação aos manequins. nA rua dos Crocodilos, a compilação de contos. Temos três histórias curtas dedicadas aos manequins: "Tratado de manequins ou o Segundo Gênese", "Tratado de manequins - Continuação", “Tratado de manequins - Final". É interessante pensar o estranhamento que causava essa forma de imitação barata do humano no início do século XIX. Talvez a forte crítica de Schulz em relação a tudo que é imitação e falso deva-se justamente a seu estranhamento e desconforto em relação a essa réplica humana. Hoje tão comum em qualquer caminhada em um centro comercial, já não causa mais desconforto. No entanto, quando surgiu, pode ter sido causa de assombro tamanha familiaridade ao corpo humano, pois na emergência desse estrangeiro/familiar o movimento de retorno é por si só disruptivo a1. Freud também irá falar sobre essa familiaridade estranha dos bonecos vivos de cera, os autômatos engenhosamente construídos, como no conto "O homem de areia", de E. T. A. Hoffmann, no qual se baseia para dar contornos aos mecanismos psíquicos implicados na sensação que faz coincidir estranho/familiar a2.

Freud (1919/1996), no ensaio "O estranho", questiona acerca dos limites do eu: o estranho é aquilo que, uma vez recalcado, retorna como familiar. Diz respeito ao estranho, assustador (unheimelich) ao mesmo tempo em que evoca o familiar (heimelich), porém recalcado. E esse familiar teria um poder de imantação, atração, ou seja, de nos capturar em 
um lugar que causa uma ruptura em nosso eu e uma sensação de estranhamento. Nesse texto, Freud também faz referência a uma rua, possivelmente uma rua de prostituição, uma rua da qual ele tenta sair, mas cai novamente nela, num movimento contínuo de afastamento e aproximação. A rua exerce uma força sobre seus passantes. Sobre essa sensação, Freud se põe a escrever. Tem-se uma tentativa, assim como no texto de Schulz, de dar bordas ao excesso. Lacan irá propor a noção de real como o que não para de não se escrever (Lacan, 1964/2008, p.101); "o real aqui é o que retorna sempre ao mesmo lugar - a esse lugar onde o sujeito, na medida em que cogita, não o encontra" (Lacan, 1964/2008, p. 55). Tomamos a escrita de Schulz como essa tentativa de circunscrever, engendrar isso que se esvai do simbólico mas que ao não cessar de não se escrever causa a própria escrita.

Freud e Schulz, contemporâneos, estão às voltas com esta questão: como escrever o que não cessa de não se escrever? Como representar o irrepresentável? A rua dos Crocodilos, sabe-se que ela está lá, mesmo ocupando um lugar que não existe; o conto é uma tentativa de circunscrever esse apagamento, esse silêncio no mapa. Ao final do conto de Schulz, começam a surgir rumores envolvendo um possível segredo referente à rua dos Crocodilos. "Mas será que devemos revelar o último segredo desse bairro, o segredo da rua dos Crocodilos cuidadosamente guardado?” (Schulz, 1934/2008, p.90). Qual seria esse segredo guardado? Poderíamos já imaginar que esse segredo não seria revelado, pois tudo na rua dos Crocodilos se faz em desvelamento, como se a linguagem não conseguisse acessá-la. O lugar é cuidadosamente mantido, exerce fascínio e tem caráter imitativo e ilusório.

Nossa língua não possui termos que dosem o grau de realidade que definam sua densidade.... a fatalidade desse bairro é que nele nada se realiza, nada chega a seu definitivum, todos os movimentos iniciados ficam suspensos no ar, todos os gestos se esgotam antes do tempo e não podem ultrapassar certo ponto morto.... Ultrapassando certo ponto de tensão, a enchente para e recua, a atmosfera se apaga, e desfloresce, as possibilidades murcham e se desmancham no nada, e as papoulas da excitação, pardas e alucinadas dissipam-se em cinzas. (Schulz, 1934/2008, pp. 91)

Esse é o lugar dos desejos vazios, pois antecipados e despertados precocemente, onde nada de fato permanece ou se solidifica. Tudo são possibilidades e proximidades de consumação, porém, da mesma forma, é esse o lugar onde tudo termina. Nas palavras de Schulz (1934/2008, p.91), "nunca a encontraremos de novo... vamos errar entre os letreiros e nos enganar mil vezes... vamos nos enredar em mal-entendidos, até que toda a nossa febre e 
excitação se evaporem num esforço vão, numa correria inútil". O segredo da rua dos Crocodilos é a sua própria dificuldade de definição. Um espaço de concessão ao novo, ao moderno, e também à corrupção dos desejos. Uma imitação barata de papel, "como uma fotomontagem de recortes de jornais deteriorados do ano passado" (Schulz, 1934/2012, p.92).

O segredo da rua dos Crocodilos não é revelado (ou é?), o narrador apenas nos adverte:

... colocamos várias vezes certos sinais de aviso, manifestamos discretamente nossas objeções. O leitor cuidadoso não será então surpreendido com o desfecho desta questão. Falamos do caráter ilusório e imitativo deste bairro, porém tais palavras têm um significado definitivo e determinado demais para resumir o caráter incompleto e indeciso desta realidade. (Schulz, 1934/2008, pp. 90)

O que o narrador nos adverte é que não há palavras que dosem o grau de realidade desse lugar, não há como terminar o que jamais começou, não há como definir o que é indefinível, nem representar o que é irrepresentável. O leitor cuidadoso é, assim, aquele que se aproxima do texto como alguém que cava com a coragem de encontrar o que não supunha. $\mathrm{Na}$ rua dos Crocodilos, ao mesmo tempo em que nos aproximamos de um lugar sem representação, um lugar de silêncio e ausência no mapa, somos a ela atraídos por todo o seu excesso e por uma sensação de estranhamento. "Apesar do nosso conhecimento sublime, sentimo-nos envolvidos na magia barata do bairro.” (Schulz, 1934/2008, p. 88).

Ao nos depararmos com "A rua dos Crocodilos", não temos como nos esquivar da pergunta: o que faríamos com um mapa que contivesse no lugar que gostaríamos de chegar um espaço em branco, apagado? "As proximidades da rua dos Crocodilos, no mapa, estavam assinaladas em branco, assim como nos mapas costumam estar demarcadas as regiões polares, os países desconhecidos ou incertos." (Schulz, 1934/2008, p. 84). E ainda, como se não bastasse não chegarmos, para o lugar de onde saímos não conseguimos mais voltar. "Vamos nos arrepender sempre de termos saído por um momento, naquela hora, da confecção de má fama. Nunca a encontraremos de novo. Vamos errar entre os letreiros e nos enganar mil vezes." (Schulz, 1934/2008, p. 91). O caminhar em um local de trânsito incerto, de bondes, trens e pessoas suspeitas. O trajeto por esse bairro é errante. "Nesse bairro de aparências e gestos vazios não se costuma dar muita importância ao destino da viagem, e os passageiros se deixam levar pelos veículos com a leviandade característica de tudo que há nesse lugar". (Schulz, 1934/2008, p. 89). 
O pequeno narrador observa e relata este lugar de caráter ilusório e imitativo. O conto é uma aproximação com mapas de caminhos incertos e com aquilo que não se encontra, muito pelo contrário, que se perde. O lugar que se procura, e que não se encontra, mas se aproxima, não é um lugar comum, é um lugar dos exageros de afetos, de ruas e becos, de casas de arquiteturas singulares. A região próxima à rua dos Crocodilos tem uma configuração diferente do restante do mapa: "apenas algumas ruas foram desenhadas, com traços pretos e nomes em letra comum, não ornamentada, diferente do nobre tipo romano das outras inscrições" (Schulz, 1934/2008, p. 84). A cartografia demarca um lugar que não merece uma letra ornamentada, mas sim uma letra comum. Um local obscuro, obtuso, mas de grande fascínio. "Provavelmente o tipógrafo recusava-se a reconhecer esse bairro como parte do conjunto urbanístico e exprimia sua objeção dessa forma singular e estigmatizante." (Schulz, 1934/2008, p. 84). Schulz nos informa que para entender tal objeção precisamos voltar a atenção para o caráter ambíguo e duvidoso de um bairro tão divergente do resto da cidade. Uma área comercial com caráter utilitário acentuado, sinal dos tempos, sinal de uma economia gananciosa, que origina um bairro parasita. Enquanto na cidade velha permanecia o comércio noturno, clandestino e o cerimonial solene, no novo bairro desenvolviam-se as formas modernas e lúcidas de comercialização. O conto vai, assim, narrando a resistência do povoado dessa pequena cidade às novas formas de comercialização de um "pseudoamericanismo, enxertado no velho solo carunchoso da urbe... viam-se ali prédios baratos, mal-construídos, com fachadas que eram caricaturas de si mesmas" (Schulz, 1934/2008, p. 84). E segue a descrição com forte crítica à modernização:

Os moradores nascidos na cidade mantinham-se longe daquele sítio habitado por marginais, pela plebe, por criaturas sem caráter e sem densidade, pela verdadeira mediocridade moral, uma espécie grosseira de ser humano que prolifera em meios efêmeros como aquele. Aqueles que, porventura, se aventurassem pelas ruas do bairro degradado, estavam sujeitos a misturarem-se e perderem-se na tentação voluntária, tudo era convidativo à imprudência, suspeito de desordem e caos. (Schulz, 1934/2008, pp. 85).

As pessoas desertoras ou desavisadas da velha ordem do bairro velho eram aquelas que se perdiam nas sujas ruas dos Crocodilos. O bairro é monocromático como em uma fotografia cinzenta, o autor compara o passeio por essas ruas ao folhear de um prospecto e suas enjoativas páginas de classificados, "entre os quais aninharam-se, feito parasitas, os 
anúncios suspeitos, os apontamentos irritantes, as ilustrações duvidosas" (Schulz, 1934/2008, p.91). Ao lermos o conto, somos quase que tomados por essa sensação de náusea e enjoo, como se algo estivesse em excesso no nosso corpo e precisasse ser expurgado. A maneira como a rua dos Crocodilos é descrita, um lugar em que tudo "desflorece, as possibilidades murcham e se desmancham no nada, e as papoulas de excitação, pardas e alucinadas, dissipam-se em cinzas" (Schulz, 1934/2008, p. 91), remete ao sentimento que o narrador tem em relação aos efeitos da passagem do tempo na crescente modernização das cidades no início do século XX. Efeitos que, aos olhos do narrador, são nocivos. O tempo age como uma espécie de inimigo; a crescente modernização na rua dos Crocodilos não vem tornar a cidade melhor, muito pelo contrário. Nas quinze histórias de Schulz, a única que faz referência a um mapa é “A rua dos Crocodilos”. O mapa dessa rua ocupa, aos olhos desse menino, um imenso local na parede de uma casa. Desenhado em folhas de pergaminho, remete-nos à busca por um passado: como se Schulz, ao escrever sobre o mapa, indicasse que jaz no coração do representável sempre algo de irrepresentável.

\section{O silêncio excessivo e a impossibilidade de representar o real}

Na relação entre psicanálise e ficção apontamos para o saber-fazer da literatura e o real da psicanálise uma via régia de aproximação de uma à outra. Segundo Certeau (2011, p. 49) a ficção não é estranha ao real, apresentando a ideia de que de que o fictious estaria mais perto do real do que o discurso dito objetivo. Para Lacan (1959, p. 22), o real se articula com o simbólico "Fictious não quer dizer ilusório, em si mesmo, enganador, mais propriamente falando, o que chamamos de simbólico'. Para Certeau (2011. p. 49) a ficção apresenta-se como um "discurso que dá forma [informe] ao real" admitindo, assim, possibilidade de representa-lo, assumindo assim a perda que ele comporta. A escrita de Schulz, ao nos transportar para um lugar ausente no mapa, mas ao mesmo tempo excessivo, nos indica de forma reiterada um ponto de articulação entre literatura e psicanálise: a impossibilidade de dar uma forma acabada, um contorno certeiro e estável ao real.

Outro aspecto importante indicado pelo conto "A rua dos Crocodilos" - que também nos aproxima da questão do real - é o sentimento de estarmos em uma caminhada que nos guia ao silêncio, porém um silêncio grávido de sons, como nos sugere o músico e inventor da poética do silêncio, John Cage. Um excesso que aparece quando a ausência se faz presente. A cada linha somos tomados por este paradoxo: há uma ausência que se faz pelo excesso. Quanto mais nos aproximamos da rua, mais nos aproximamos desse silêncio no mapa. 
Imaginamos um ruído ensurdecedor que vem dessa rua, e, em seguida, ao nos aproximarmos da vizinhança da rua, somos tomados por um silêncio, um silêncio prenhe de sons. Excessivo.

A locomoção é feita pelos bondes, o maior triunfo da ambição dos vereadores, empurrados por carregadores municipais; porém, a coisa mais estranha é a comunicação ferroviária da rua dos Crocodilos. "A multidão aguarda um trem no final do dia, trem que não se sabe se passa, e as pessoas ficam em dois pontos diferentes, sem concordar com o local de parada" (Schulz, 1934/2008, p. 89). Aqui percebemos a total desordem do local que Schulz tenta imprimir em sua descrição. As pessoas que esperam sem nenhuma ordem ou sentido são descritas como silenciosas, aguardam de perfil como uma fileira de máscaras pardas de papel, assim como os bondes, que também parecem feitos de papel. Tudo nesse local se imprime como falso e frágil. Agiotagem, suborno, negociações nervosas e funcionários corruptos imperam na rua. $\mathrm{O}$ trem parte pela estrada de ferro acompanhado por uma multidão lenta e desiludida que finalmente dissipa-se.

Na história da cartografia, o silêncio no mapa é mais do que uma simples ausência de alguma coisa. Os silêncios podem revelar tanto quanto escondem, os silêncios podem tomar por vezes a parte determinante da mensagem cartográfica. Assim, exatamente como na comunicação verbal, o silêncio é mais do que o mero correlato do que não foi ouvido, e, no caso do mapa, o silêncio não é o oposto do que foi mostrado. O silêncio não se reduz ao campo do fenômeno acústico-sonoro, "o silêncio não é acústico. O silêncio é uma mudança da mente. Eu pensei, honesta e ingenuamente, que existia de fato um silêncio", confessa Cage (1959, p. 135), após sua experiência na câmara anecoica na Universidade de Harvard. "Por mais que tentemos fazer silêncio, não o podemos: não há silêncio que não esteja grávido de sons". A multidão silenciosa de Schulz lembra, reiteradamente, a relação entre ausência e excesso presente nos silêncios. O silêncio que se faz por excesso de sons, ou de sentidos, o que cabe dentro de um silêncio.

Enquanto na cidade velha reinava ainda o comércio noturno, clandestino, com seu cerimonial solene, naquele bairro novo desenvolveram-se logo formas modernas e lúcidas de comercialização. O pseudoamericanismo, enxertado no velho solo carunchoso da urbe, desabrochou ali numa exuberante mas vazia e descorada vegetação de ordinária e grosseira vaidade. Viam-se ali prédios baratos, mal construídos, com fachadas que eram caricaturas de si mesmas, prédios cobertos de um estuque monstruoso de gesso gretado. Casas de subúrbio velhas e tortas receberam 
pórticos feitos às pressas, que só vistos de perto poderiam ser desmascarados como imitações pobres das instalações metropolitanas. (Schulz, 1934/2008, pp. 84)

Existe um exagero na caricatura. Quando dizemos que algo é caricatural, salientamos o exagero de um traço, uma marca aumentada. Schulz faz uma forte crítica a tudo aquilo que é barato, fácil, imitado, e também caricatural, exagerado, excessivo. A referência ao gesso também caminha ao lado de uma definição daquilo que não tem substância, apenas serve para imitar outra estrutura. Pai e filho seguem sua caminhada pelas lojas de alfaiataria, e seu contato com os vendedores e vendedoras é narrado da mesma forma que o local, como se a eles se misturassem personagens que são descritos como a rua, destituídos de qualquer valor. "A multidão de transeuntes monótonos trafega por entre quadrados escuros e sujos, cheios de produtos baratos, grandes manequins de cera e bonecas de salão de cabeleireiros" (Schulz, 1934/2008, p. 90). A rua dos Crocodilos exala odores de devassidão e corrupção, que, mesmo assim, orgulham os moradores da cidade, que não precisam se privar de nada, pois podem também usufruir da devassidão da cidade grande.

\section{O mapa das ausências e dos apagamentos}

O encontro com a obra de Bruno Schulz nos lembrou a todo o momento sobre como podemos representar os apagamentos. Um escritor que viveu o trauma da guerra e que de lá lutou para manter viva sua produção, enviando-a a amigos. Em vão, seu material se perdeu. Sabemos que existe algo de sua produção a que jamais teremos acesso e é com esse pensamento que lemos Schulz e que lemos sobre a rua sem representação no mapa, mas que está lá e nos causa uma sensação de imantação. Para além disso, a própria escrita de Schulz é uma forma de se haver com um passado através da percepção infantil, que transita o tempo todo entre o real e o imaginário.

O que aprendemos com Freud sobre a memória é que é sobre aquilo que esquecemos que construímos nossa narrativa pessoal. Como se a casa em que moramos na infância fosse o lugar ao qual sempre voltamos porque é lá que ficou aquilo que esquecemos, o que recalcamos: nosso passado soterrado. Não somos apenas o que pensamos ser. Somos mais: somos o que lembramos, esquecemos, as palavras que trocamos, os enganos que cometemos, os impulsos a que cedemos. "Todos somos convocados a responder pela infância, a responder por um momento que aparentemente não nos diz respeito, porque se trata preponderantemente da encarnação do desejo de nossos pais." (Costa, 2001, p. 165). Retornar a essa casa, hoje 
demolida, e contar-se desde lá é uma tarefa da ordem de um impossível, mas que carrega esse jogo que faz com que construamos uma casa própria - e nova. "Responder pela infância pode ser o que permita a saída de posições instrumentais", aponta Costa (2001, p. 165). Responder desse lugar é haver-se com seu sintoma, sempre singular. Lembrando o famoso postulado freudiano de que a histérica sofre de reminiscências (1985/1973), observamos que é essa lembrança que estava diretamente relacionada a um sintoma que representava, no caso das histéricas de Freud, uma perda libidinal importante.

Muitas das primeiras mulheres que Freud atendeu foram enfermeiras de seus pais, acompanhando-os até a morte. Esse acompanhamento produzia uma "memória" de conversão. Se por um lado aqui se coloca que a memória patologiza, por outro também é possível afirmar que um sintoma é uma memória: cumpre fundamentalmente uma função de representação. (Costa, 2001, pp. 166)

Ou seja, aquilo que está marcado no corpo, o sintoma, é a representação de um apagamento. "Neste sentido, faz parte da sua própria constituição: é a memória como apagamento. A produção de seu registro faz parte da forma de sintoma em que ele é produzido." (Costa, 2001, p. 166). "A rua dos Crocodilos” não está no mapa, mas, ao mesmo tempo, está. Sua história de vida (de Schulz) foi (quase que) apagada, mas algo permaneceu lá. Percebemos essa metáfora no documentário de Benjamin Geissler, Findingpictures (2009), que retrata a busca pelos desenhos de Bruno Schulz feitos na parede do quarto dos filhos de Landau quarenta anos após a sua morte. A busca pelos desenhos de Schulz trouxe à superfície aquilo que sempre esteve lá, abaixo de uma fina camada de tinta, esperando ser descoberto. Assim, se tivermos como pressuposto que o sintoma é a representação que permite fazer registro de um apagamento, poderemos pensar a obra de Schulz como o que de um apagamento insiste em ser registrado. $\mathrm{O}$ escritor morto pelo nazismo, que teve que ter sua obra recuperada por outros para hoje poder existir, é o mesmo autor que fala de um lugar sem representação em um mapa. Parece que a obra de Schulz se localiza sob uma superfície e precisa ser extraída por um outro para poder surgir/emergir.

O horizonte inicial da teoria psicanalítica era justamente este: trazer ao consciente o que estaria no inconsciente. Quando Freud começou a ouvir as suas histéricas, descobriu que o sintoma muitas vezes era produzido em função de uma cena recalcada. Assim que as pacientes começavam a falar, os sintomas dissipavam-se. Fazer falar é produzir na memória o recalcado que faz registrar pelo apagamento. Na busca (pela rua dos Crocodilos) nos 
aproximamos de uma região em branco em um mapa (figuração do simbólico) que não encontra representação, "nossa língua não possui termos que dosem o grau de realidade que definam sua densidade", aponta Schulz (1934/2008, p. 91). É essa a imagem que Schulz faz desse lugar no mapa, ao mesmo tempo em que toda a sua escrita é uma forma de retorno a um momento da infância, um momento anterior à própria aquisição da linguagem. Seu pano de fundo é o tempo, aquele que tudo devora, e o encontro é aquele que se faz através da busca por esses vestígios da memória. A indicação de que há algo que não se representa (o real) poderia ser o tema principal de "A rua dos Crocodilos".

E buscar esse lugar é o que permite dar contorno a uma suposta ausência. Falamos aqui em se aproximar, pois não se trata de, através da busca, achar algo que já estaria lá, obtendo assim uma resposta com nosso "achado" ao enigma que faz com que nos movimentemos. O inconsciente não é um baú de memórias em que acabaríamos, através do processo de análise, adentrando ao seguir os passos de uma "caça ao tesouro". Buscamos algo que não está lá, mas que se apresenta no próprio processo de buscar, em um tempo retardatário, em um só depois. É daquilo que do passado retorna no presente que estamos falando, "passado na medida em que é historiado no presente porque foi vivido no passado" (Lacan, 1953-54/1986, p. 21).

Para Foer (2008), a escrita de Schulz é como a busca que visualizamos no documentário de Geissler: é uma busca pelo que reside atrás da fina camada de tinta em uma parede e que apenas insinua encostar na superfície. Ela tenta encostar na superfície da vida, que, comparada à superfície da terra, é tão fina quanto uma casca de ovo ou quanto uma pintura na parede. Elas são muito grandes ou muito magníficas para estarem contidas em meros fatos. Elas estão apenas tentando acontecer, estão checando se o solo da realidade pode suportá-las. E elas rapidamente se retiram, temendo perder sua integridade na fragilidade da realização. O que Foer refere, em outras palavras, é que a literatura de Schulz está sempre às voltas com este enigma que aponta para o real, o real da realização. Assim como o faz a psicanálise, sendo este um dos aspectos de aproximação entre ambas.

Os grandes momentos da nossa vida não podem ser descritos como meros fatos. $\mathrm{Na}$ escrita eles apontam o enigma, ou checam o solo da realidade antes de poderem acontecer no papel. O que buscamos nas histórias de ficção, ao final do dia, segundo Foer, é um momento de fruição que vai ao encontro daquilo que reside abaixo da fina superfície da nossa mera existência. As histórias cavam rumo aos grandes fatos de nossas vidas. Elas nos dão acesso mesmo que somente por algumas horas, mesmo que somente quando deitamos na cama na hora de dormir - ao que está sob a superfície da banalidade de nosso cotidiano. Mas, para 
Foer, "cavar" é muito pouco para definir o trabalho da escrita de Bruno Schulz. O que ela revela é nada mais do que um conto de fadas.

Branco (2011, p. 107) lembra que a poesia possui uma desparecência poética, ou seja, comporta uma lógica própria, e também, no sentido blanchotiano, "a literatura vai para si própria, para sua essência, que é seu desaparecimento" (Blanchot, 2005, p. 205). A autora cunha o termo superfície de poema para salientar o caráter da poesia de se meio-dizer, ser não toda: “o poema por aspirar à verdade só pode se meio-dizer" (Branco, 2011, p.107). Observamos na poesia de Schulz, como salienta Foer, essa relação de sua escrita com a superfície. Se a realidade é fina como o papel, encostar na realidade seria rasgar o papel, furar, comprometer. Lembremos o famoso aforismo de Lacan (1966/1998, p. 870): a verdade não pode se dizer por inteiro, só pode se meio-dizer.

O poder de revelação de um poema enreda-se em torno de um enigma, de modo que a verificação desse enigma faça todo o real de impotência da potência do verdadeiro. Nesse sentido, "o mistério das letras” é um verdadeiro imperativo. Quando Mallarmé sustenta que "sempre deve haver enigma em poesia", funda uma ética do mistério que é o respeito, pelo poder de uma verdade, de seu ponto de impotência. O mistério é de fato que toda a verdade poética deixe em seu centro o que ela não tem o poder de fazer vir à tona. (Branco, 2011, pp. 109)

Para a psicanálise, a verdade jamais será toda, pois essa totalidade acarretaria a abolição do inconsciente. $\mathrm{O}$ poeta faz sua arte com a mesma matéria do inconsciente e sua criação se antecipa às formulações que a psicanálise teoriza. A psicanálise, por sua vez, encontra na literatura de Schulz a operação de um de seus pressupostos: a impossibilidade de a verdade dizer-se toda. Existe um ponto dessa impossibilidade que coincide, sabemos, com os aforismos de Lacan sobre o ponto de inexistência da relação sexual e da mulher (Lacan, 1974-75/n.d.).

O inconsciente, como um saber insabido, determina efeitos, e o que denominamos sujeito é um efeito do inconsciente que, instantâneo e fugaz, se abre para logo se fechar. Uma letra a mais faz do copo, corpo, para logo alterar-se em porco, surgindo na palavra do sujeito um novo significante, cuja verdade aponta para o gozo sexual no limite, impossível de dizer, o que se insta a que se diga e se escreva. (Vidal, 2000, pp. 74) 
O movimento feito em direção à escavação/extração dos desenhos de Schulz (os contos de fadas rabiscados na parede do quarto das crianças do soldado alemão) é como sua própria escrita. É uma escrita que quer encostar no real (aquém da superfície), mas que se permite ficar no quase, na hesitação, na impossibilidade de dizer-se toda.

... não des-cobre nada que já estava lá, encoberto, aguardando o grande dia, numa leitura solitária de um antigo trauma de infância. Não há nada coberto a ser desvelado. O que há é uma escrita vacilante passível de inúmeras mudanças e reachados que surge ao nascer de uma análise. Uma inquietante maneira do sujeito se apropriar de seus próprios rabiscos (Salum, 2016, p. 53)

É, com efeito, pelo seu dizer que o sujeito constrói, mediante as palavras que pronuncia ou cala, o Real a3 que será doravante o seu (Lacan, 1986). A invenção sugere assim um saber-fazer-com esse passado que se atualiza no presente, transformando-o em um outro vivido. Esse movimento também poderia ser encontrado no processo da escritura, como nos sugere Barthes (1984), pois tanto na escritura quanto no processo de análise, é ao nos aproximarmos do lugar que resiste à representação que acabamos imprimindo nossa marca, caminhando para a invenção ou para a escritura. O que aprendemos com a psicanálise e também com a teoria da leitura em Barthes (1984) e Compagnon (2007), é que é preciso que uma abertura surja para que algo novo possa se produzir. Tais zonas de apagamentos, tão salientes na escrita de Schulz, fazem com que o encontro com sua escritura pulsante produza uma leitura viva e uma nova escritura. Podemos pensar em algo da sua obra (de Schulz) que "reencontra no inconsciente de quem o encontra um 'eco pulsante' que faz com que se queira produzir algo com este material, que se extraia, que se conecte novamente à realidade através da criação/invenção" (Vidal, 2000, p.71). Extrair do material para contornar a realidade através da criação/invenção é o horizonte do trabalho com o mapa de ausências e apagamentos em Bruno Schulz.

\section{Considerações Finais}

Como afirmou o escritor polonês Stanisław Ignacy Witkiewicz, as frases de Schulz são "como meteoros" que iluminam paisagens desconhecidas do próprio tecido da realidade. É no arrebatamento criador, ao olhar de uma criança, em um amadurecer infância adentro, 
que vamos entrando neste terreno de linguagem extremamente rebuscada, fragmentária, um quebra-cabeças no qual a criança enxerga o mundo. A relação entre a prosa e a poesia, o sentimento de estranhamento e familiaridade, a profunda tentativa labiríntica de narrar a experiência, são fatores que tornam a obra de Schulz uma escrita de potência singular. A prosa poética para o escritor polonês, nas palavras de Foer, questiona o grau de realidade dos acontecimentos: "há coisas que não podem acontecer totalmente, até o fim. São grandes, são magníficas demais para caber num acontecimento. Apenas tentam acontecer, só verificam se o solo da realidade as suporta". (Foer, 2008 p. 9). Em "A rua dos Crocodilos", Bruno Schulz, através do olhar do infantil, em uma espécie de retorno a um momento mítico, nos conduz pelas ruas de uma região ausente no mapa, uma região excessiva e ao mesmo tempo sem representação no mapa. E, ainda, o trato com a memória e com o mito, características marcantes na escrita do autor, remetem-nos à importância que a psicanálise sempre atribuiu às zonas de apagamento na constituição da memória. Conduzir o leitor pelos caminhos de uma região que nos causa uma sensação de imantação, sedução e estranhamento e que quando dela tentamos nos livrar nos perdemos ainda mais é o que produz a escrita de Bruno Schulz.

O "mapa de ausências e de apagamentos" em "A rua dos crocodilos" de Bruno Schulz nos permite articular e fazer ressoar alguns conceitos fundamentais da formulação psicanalítica, como a memória e as zonas de apagamento, o conceito de estranho e conceito de real. Testemunhar essa articulação indica a importância que a literatura pode ter na formação do psicanalista - como já o lembrava Freud em “Análise Leiga”. Através do olhar do narrador infantil de Schulz nos entregamos a uma caminhada atenta aos desvios, à sensação de desejo e estranhamento e à busca sempre em vão de adentrar em uma região sem representação busca que em seu fracasso alimenta a caminhada. Nos aproximamos, assim, do impossível posto em cena através do conceito lacaniano de real e da própria experiencia analítica, ou seja, o real como aquilo que escapa e que tentamos circunscrever: o que não pára de não se escrever (Lacan, 1972-73/2008, p.101).

\section{Referências}

Attridge, D. (2011). Introdução. In J. M. Coetzee, Mecanismos internos: Ensaios sobre literatura (2000-2005) (pp. 5-10). São Paulo: Companhia das Letras.

Barthes, R. (1984). A câmara clara. Rio de Janeiro: Nova Fronteira. 
Benjamin, W. (2000). Rua de mão única: Infância berlinense: 1900. In W. Benjamin, Obras escolhidas (Vol. 3, pp. 239). São Paulo: Editora Brasiliense. (Original publicado em 1938).

Blanchot, M. (2005). O livro por vir. São Paulo: Martins Fontes.

Branco, L. C. (2011). Chão de letras: as literaturas e a experiência da escrita. Belo Horizonte: Editora UFMG.

Cage, J. (1959). Lecture on something. In J. Cage, Silence: lectures and writings (pp. 128145). London: Marion Boyars.

Certeau, M. (2011). História e psicanálise: entre ciência e ficção. Belo Horizonte: Autêntica.

Coetzee, J. M. (2011). Bruno Schulz. In J. M. Coetzee, Mecanismos internos: Ensaios sobre literatura (2000-2005) (pp. 65-76). São Paulo: Companhia das Letras.

Compagnon, A. (2007). O trabalho da citação. Belo Horizonte: Editora UFMG.

Costa, A. (2001). Corpo e escrita: Relações entre memória e transmissão da experiência. Rio de Janeiro: Relume Dumará.

Ficowski, J. (2004). Regions of the Great Heresy - Bruno Schulz: A Biographical Portrait. Nova York: W.W. Norton \& Company. (Obra original publicada em 1967)

Foer, J. S. (2008). Preface. In B. Schulz, The Street of Crocodiles and Other Stories (pp. 610). New York: Penguin. (Obra original publicada em 1934)

Freud, S. (1996). O estranho. In Edição standard das obras psicológicas completas de Sigmund Freud (Vol. 17, pp. 234-276). Rio de Janeiro: Imago. (Obra original publicada em 1919).

Freud, S. (1973). Estudios sobre la histeria. In Obras completas de Sigmund Freud (Vol. 1, 3a ed.). Madrid: Biblioteca Nueva. (Obra original publicada em 1895)

Gombrowicz, W. (2012). Bruno Schulz no diário. In: B. Schulz, Ficção completa (pp. 391401). São Paulo: Cosac Naify. (Obra original publicada em 1934)

Lacan, J. (1956-1957). O Seminário, livro 4: As Relações de Objeto. Rio de Janeiro: Jorge Zahar Editor.

Lacan, J. (1986). O seminário, livro 1: os escritos técnicos de Freud. Rio de Janeiro: Jorge Zahar. (Obra original publicada em 1953-54)

Lacan, J. (n.d.). $O$ seminário, livro 22: R.S.I. Recuperado de http://lacanempdf.blogspot.com/2017/03/o-seminario-22-rsi-jacques-lacan.html. (Obra original publicada em 1974-75).

Lacan, J. (2008). O Seminário, livro 11: os quatro conceitos fundamentais da psicanálise. Rio de Janeiro: Jorge Zahar (Obra original publicada em 1964). 
Lacan, J. (2008). O seminário, livro 20: Mais, ainda. Rio de Janeiro: Jorge Zahar (Obra original publicada em 1972-73).

Lacan, J. (1998). A ciência e a verdade. In J. Lacan, Escritos (pp. 869-892). Rio de Janeiro: Jorge Zahar. (Obra original publicada em 1966)

Milosz, C. (2012). Algumas palavras sobre Bruno Schulz. In B. Schulz, Ficção completa (pp. 11-12). São Paulo: Cosac Naify. (Obra original publicada em 1989)

Pereira, L. S. (2014). A ficção na psicanálise. Porto Alegre: APPOA/Instituto APPOA.

Salum, L. (2016). Fragmentos: Sobre o que se escreve de uma psicanálise. São Paulo: Iluminas, 2016.

Shakespeare, W. (n.d.). A tempestade. Brasília: Editora da UnB.

Schulz, B. (2012). Ficção completa. São Paulo: Cosac Naify.

Schulz, B. (2008). The Street of Crocodiles. New York: Penguin. (Obra original publicada em 1934)

Vidal, Eduardo. (2000). O estilo é o objeto. In L. Branco, R. Brandão (Org.), A força da letra: estilo, escrita, representação (pp. 133-141). Belo Horizonte: Editora da UFMG.

Wurth, K. B. (2011). Old and new medialities in Foer's Tree of Codes. CLCWeb: Comparative Literature and Culture, 13(3), 1-8. doi:10.7771/1481-4374.1800

\section{Endereço para correspondência}

\section{Camila Backes dos Santos}

Rua Correa Lima, 640 apto 302, Porto Alegre - RS, Brasil. CEP 90850-250

Endereço eletrônico: camibackes@gmail.com

\section{Simone Zanon Moschen}

Rua Tomaz Gonzaga, 430 casa 8, Porto Alegre - RS, Brasil. CEP 91340-480

Endereço eletrônico: simoschen@gmail.com

Recebido em: 27/03/2019

Reformulado em: 05/07/2019

Aceito em: 26/10/2019

\footnotetext{
Notas

* Psicanalista. Doutora em Psicologia Social e Institucional pela UFRGS. Pós-doutoranda em Diversidade Cultual e Inclusão Social na Feevale.

** Psicanalista. Doutora em Educação pela UFRGS. Professora do Programa de Pós-Graduação em Psicanálise: Clínica e Cultura e do Programa de Pós-Graduação em Educação da UFRGS.
} 
${ }^{1} \mathrm{O}$ movimento de retorno é disruptivo porque aponta uma separação entre as realidades internas e externas, entre o eu e o outro, analisadas por Freud através do fenômeno do duplo. O fenômeno do duplo refere-se ao retorno à cena na qual imperava o narcisismo primário, momento no qual o ego não se distinguira ainda nitidamente do mundo externo e de outras pessoas. Por isso, a imagem do duplo, ao mesmo tempo que aterroriza e persegue, também fascina e imanta o sujeito.

${ }^{2} \mathrm{Na}$ literatura, o estranho refere-se a uma experiência do estranho causada no leitor ao criar-se uma personagem - como no conto de E.T.A. Hoffmann, a boneca Olímpia - que o leitor não sabe se é um humano ou um autômato, prendendo assim a sua atenção sem resolver a questão.

${ }^{3}$ O Real com "R" maiúsculo faz referência aos três registros operados por Jacques Lacan: Real, Simbólico e Imaginário.

Financiamento: CAPES/CNPQ.

Este artigo de revista Estudos e Pesquisas em Psicologia é licenciado sob uma Licença Creative Commons Atribuição-Não Comercial 3.0 Não Adaptada. 